\title{
The new geospatial data of the Friuli Venezia Giulia Region (Italy): a geomatic challenge
}

\author{
Alberto Beinat $^{\mathrm{a}, *}$, Massimiliano Basso ${ }^{\mathrm{b}}$, Elena Viero ${ }^{\mathrm{b}}$ \\ ${ }^{a}$ University of Udine - DPIA, alberto.beinat@uniud.it \\ ${ }^{b}$ Insiel S.p.a., massimilano.basso@insiel.it, elena.viero@insiel.it \\ * Corresponding author
}

Keywords: True ortophoto, Lidar, DTM, DSM, DBM, Hyperspectral orthoimage, Technical map, Territorial Data Base

\begin{abstract}
:
Friuli Venezia Giulia Region occupies a morphologically various territory, considerably anthropized and dynamic, historically subject to significant seismic and hydrological events.

In order to have adequate tools for analysis and planning, the regional administration maintains a complete, updated and accurate mapping of the territory, investing adequate resources in the acquisition of advanced cartographic products.
\end{abstract}

Since the 1970s the region has had a Regional Technical Map at a scale of 1:5000, which became digital in 1990 on the occasion of the second edition and has been subject to partial updates since then. After an initial experimentation, the FVG Region started in 2017 the radical renewal of its geospatial databases, expanding them with new cartographic products, and entrusting the realization to a group of private firms specialized in the necessary geomatic techniques. For specific metrics, quality of information and spatial extension, the products thus created can be placed at the top of the Italian cartographic production.

The first product realized is the high density airborne Lidar survey of the entire regional territory (over 7900 square kilometers) in the form of point cloud. According to the specifications, it has an average minimal density of "first pulse" of 16 points per square meter, reduced to $10 \mathrm{p} / \mathrm{sqm}$ for mountain areas above $1000 \mathrm{mlm}$, and a maximum planoaltimetric tolerance of $+/-25 \mathrm{~cm}$. The survey of the territory is composed by partially overlapping strips, about $600 \mathrm{~m}$ wide, acquired from $500 \mathrm{~m}$ above the ground. The over 300 billion points registered have been labeled by means of classification algorithms based on geometric rules and artificial intelligence and divided into the classes terrain, vegetation, road structures, power lines, water and "other". From the pointcloud, further raster maps were elaborated at 0.5 meter intervals, such as the digital land surface (DSM) derived from the "first returns" (the points closest to the sensor) and that produced with the "last returns" (the most distant ones), the digital terrain model (DTM), the building model (DBM) and other specific products (e.g. hillshade).

The second realization of considerable quality is the ortophotomosaic of the entire territory, based on the generation of "True" orthophoto, acquired on 4 bands (RGB and NIR), with a pixel size of $10 \mathrm{~cm}$ and a georeferencing tolerance of less than $35 \mathrm{~cm}$. The product derives from the elaboration of aero-photogrammetric strips properly overlapped, acquired at a resolution of $8 \mathrm{~cm} /$ pixel, such as to allow the subsequent production of a new numerical vector cartography at a scale of 1:1000/1:2000 and 1:5000.

A further product, aimed in particular at environmental analysis, is the hyperspectral ortho-rectified image at a resolution of 1 meters/pixel. The range of frequencies acquired is between 400 and $1000 \mathrm{~nm}$, divided into 186 bands with 16 bit radiometric resolution; with the exception of Trieste where there are 125 bands at 14 bit.

The new Digital Regional Technical Map is based on photogrammetric restitution, possibly integrated by Lidar surveys, and currently covers the territory of the former Province of Trieste. The extension to the urban areas of Udine, Pordenone and Gorizia is currently under working.

This map, called DBTfvg (Territorial Data Base FVG), represents a modern and advanced cartographic product that stands out for its adherence to the GeoUML standard, according to the requirements of the INSPIRE Directive and the prescriptions of the Italian laws. Among the distinctive factors, they include the adoption of two different nominal scales for urban areas $(1: 1000)$ and for the remaining territory (1:5000), and the representation of buildings both according to the roof footprint and without roof overhang. 
For the remaining areas of the region that will not be covered by the DBTfvg, the Administration has commissioned an innovative map obtained by an automatic classification of the ortophotomap, able to extract the geometry of the main cartographic classes: buildings, roads, green and agricultural areas.

The list of cartographic products is completed with the MMS - Lidar and photographic - survey of the roads of the main urban areas that will integrate the Road Cadastre of the FVG Region, which is also being completed.

In addition to describing the salient features of the mentioned products, the work aims to illustrate some significant "lessons learned" regarding the technical and operational difficulties encountered in the production of data, as well as the problems and solutions devised to make the data available to users. An overview of early projects exploiting the recently acquired cartographic data completes the discussion. 